\author{
D-ח-A-ח-D 型非掺杂小分子空穴传输材料的合成 \\ 及其在反向钙钛矿太阳能电池中的应用 \\ 王梦涵 ${ }^{\dagger}, a$ 万里 ${ }^{\dagger}, b$ 高旭宇 ${ }^{a}$ 袁文博 $^{a}$ 方俊峰*,b \\ 陶友田*,a 黄维 ${ }^{a, c}$ \\ ( ${ }^{a}$ 江苏省柔性电子重点实验室 南京工业大学先进材料研究院 南京 211816) \\ ( ${ }^{b}$ 中国科学院宁波材料技术与工程研究所＼cjkstart宁波 315201) \\ ( ${ }^{c}$ 西北工业大学柔性电子研究院 西安 710072)
}

\begin{abstract}
摘要 设计合成了三种以(甲氧基)三苯胺为给体(Donor, D), 苯环为共轭 $\pi$ 桥, 羰基(或双氰基乙烯基)为受体(Acceptor, A)的 D- $\pi-A-\pi-D$ 型有机小分子空穴传输材料 1-T、1-OT 和 1-OTCN. 对三个化合物的热稳定性、光物理以及电化学性 质进行表征, 并将它们作为空穴传输材料运用至钙钛矿太阳能电池中, 研究其光伏特性. 实验结果表明, 通过引入具 有不同给(吸)电子能力的基团，可对材料的光电性质进行有效调控. 基于小分子空穴传输材料 1-T、1-OT 和 1-OTCN 的非掺杂反向钲钛矿太阳能电池器件光电转化效率(PCE)分别为 $13.0 \%$ 、14.4\%以及 $16.8 \%$. 其中, 基于甲氧基和双氰基 修饰的 1-OTCN 电池器件, 由于空穴传输层与钻钛矿界面发生更有效的电荷跃迁和收集, 电荷复合较少, 因此器件性 能最佳, 1-OTCN 的疏水性质使得其对应器件效率和水氧稳定性均优于常用空穴传输材料 PEDOT:PSS (PCE: 13.0\%). 关键词 钙钛矿太阳能电池; 有机小分子空穴传输材料; 三苯胺; D- $\pi-A-\pi-D$; 非掺杂; 稳定性
\end{abstract}

\title{
Synthesis of $D-\pi-A-\pi-D$ Type Dopant-Free Hole Transporting Materials and Application in Inverted Perovskite Solar Cells
}

\author{
Wang, Menghan ${ }^{\dagger, a}$ \\ Wan, $\mathrm{Li}^{\dagger}, b$ \\ Gao, $\mathrm{Xuyu}^{a}$ \\ Yuan, $\mathrm{Wenbo}^{a}$ \\ Fang, Junfeng*,b \\ Tao, Youtian*,a Huang, Wei ${ }^{a, c}$ \\ $\left({ }^{a}\right.$ Key Lab for Flexible Electronics, Institute of Advanced Materials, Nanjing Tech University, Nanjing 211816) \\ ( ${ }^{b}$ Ningbo Institute of Materials Technology and Engineering, Chinese Academy of Sciences, Ningbo 315201) \\ ( ${ }^{c}$ Shaanxi Institute of Flexible Electronics, Northwestern Polytechnical University, Xi'an 710072)
}

\begin{abstract}
Perovskite solar cells (PVSCs) have recently gained much attention for the advantages of low cost and high efficiency. Based on the different device structures, PVSCs can be simply classified into conventional and inverted categories. Compared with the inverted devices, conventional PVSCs generally exhibited higher PCE. Especially, a milestone PCE value of $24.3 \%$ was obtained in conventional PVSCs. However, the complexity and high-temperature process in device fabrication further limit their application in flexible and large-scale devices, while the inverted PVSCs can make up the shortcomings of the conventional PVSCs. Commonly, PVSCs devices contain electrodes, electron/hole transporting layers and the perovskite layer. Among the function layers, hole transporting layers (HTLs) play a crucial role in improving the photovoltaic performance of inverted PVSCs. From the materials point of view, the efficient hole transporting materials (HTMs) are mostly inorganic compounds and polymers. On the other side, taking advantages of easy modification, low price, easy preparation and homogeneity in batches, small molecular HTMs afford superior promising in fabricating efficient and stable PVSCs. However, up to date, small molecular HTMs are relatively less explored. To enrich the material species of small molecular HTMs and illustrate their superiorities in constructing stable PVSCs, in this paper, we designed and synthesized three D- $\pi$-A- $\pi$-D type small molecular HTMs based on triphenylamine (TPA) unit, namely 1-T, 1-OT and 1-OTCN. The optoelectronic properties of these molecules were modified by introducing different electron acceptor/donor groups. Afterwards, employing as dopant-free HTMs in inverted PVSCs, the three small molecules demonstrated distinguished performance. We found that introduction of electron-donating methoxy into 1-T, 1-OT exhibited increased energy levels and hole mobility. On the other
\end{abstract}

*E-mail: fangjf@nimte.ac.cn; iamyttao@njtech.edu.cn

†共同第一作者. These authors contributed equally to this work.

Received June 6, 2019; published June 28, 2019.

Supporting information for this article is available free of charge via the Internet at http://sioc-journal.cn.

Project supported by the National Key Research and Development Program of China for the Joint Research Program between China and European Union (No. 2016YFE0112000), National Natural Science Foundation of China (No. 61761136013), and the Natural Science Foundation of Jiangsu Province (No. BK20160042).

国家重点研发计划政府间国际科技创新合作重点专项中国与欧盟合作项目(No. 2016YFE0112000)、国家自然科学基金国际 (地区) 合作与交流项目(No. 61761136013)和江苏省自然科学基金杰出青年基金项目(No. BK20160042)资助. 
hand, the energy levels of 1-OTCN were down-shifted compared to 1-OT, which was attributed from the stronger electronwithdrawing ability of dicyanovinylene group than carbonyl group. Among the devices with new HTMs, 1-OTCN based PVSCs achieved the best PCE of $16.8 \%$, with open-circuit voltage $\left(V_{\mathrm{OC}}\right)$ of $1.09 \mathrm{~V}$, short-circuit current density $\left(J_{\mathrm{SC}}\right)$ of 20.13 $\mathrm{mA} \cdot \mathrm{cm}^{-2}$ and fill factor $(\mathrm{FF})$ of $78 \%$. Compared with other HTMs, the higher $J_{\mathrm{SC}}$ of 1-OTCN based PVSCs was ascribed from more efficient charge transfer and extraction in the interface of HTL/perovskite. Moreover, in contrast with the hydrophilicity of PEDOT:PSS, the hydrophobicity of 1-OTCN contributed to the satisfactory stability of PVSCs.

Keywords perovskite solar cells; organic small molecular hole transporting materials; triphenylamine; D- $\pi$-A- $\pi$-D; dopantfree; stability

\section{1 引言}

随着世界人口及经济体量的快速增长, 人们常用的 煤炭及石油等不可再生能源日益贵乏. 为了实现可持续 发展, 科研工作者在不断开发地球上的可再生清洁能 源, 例如风能、潮汐能、生物质能、地热能、太阳能 等 ${ }^{[1]}$. 太阳能作为地球上最为丰富的可再生清洁型能源 之一, 利用太阳能将有效缓解人们当前所面临的能源危 机及环境污染 ${ }^{[2]}$. 自 2009 年钙铁矿太阳能电池首次被报 道以来, 其光电转化效率(Power Conversion Efficiency, $\mathrm{PCE})$ 实现了从 $3.8 \%$ 到 $24.3 \%$ 的飞跃 ${ }^{[3 \sim 8]}$, 效率远远领先 于其它新一代太阳能电池, 有望取代硅基太阳能电池, 实现商业化 ${ }^{[9-12]}$.

平面钙钛矿太阳能电池可分为正向 (n-i-p)和反向 (p-i-n)两种器件结构 ${ }^{[13,14]}$. 目前基于正向结构的钙钛矿 太阳能电池普遍具有较高的 PCE, 然而其器件制备过程 繁琐，且往往需要高温的工艺条件，因此极大地限制了 正向器件结构在柔性及大面积电池方向上的应用 ${ }^{[15 \sim 20]}$. 然而, 反向钙钣矿太阳能电池器件制备条件相对温和, 工艺简单, 可以弥补正向电池结构在基底选择以及大面 积制备上的局限性.

反向钙针矿太阳能电池主要由电极、空穴(电子)传 输层以及钙铁矿层构成, 其中空穴传输层对器件光伏性 能有极大的影响, 它可以调节阳极功函数, 提高阳极部 分对空穴的收集效率, 减少电荷在界面的复合. PEDOT:PSS 是一种经典的空穴传输材料, 因其具有优异 的空穴传输能力及较高的可见光透射率, 常用于有机发 光二极管、有机太阳能电池以及反向钙钛矿太阳能电池 中 $^{[21 \sim 23]}$. 然而, PEDOT:PSS 层状结构的三维不均匀性引 起的导电各向异性, 可能会限制其对电荷载流子的有效 收集 ${ }^{[24,25]}$. 其次, PEDOT:PSS 的最高占据分子轨道 $(-5.1 \sim-4.9 \mathrm{eV}$ ) 通常高于钙钛矿的电离电位(常用 $\mathrm{CH}_{3} \mathrm{NH}_{3} \mathrm{PbI}_{3}\left(\mathrm{MAPbI}_{3}\right)$ 电离电位为 $\left.-5.4 \mathrm{eV}\right)$. 能级差过 大会促使 $\mathrm{MAPbI}_{3} / \mathrm{PEDOT}$ :PSS 界面产生较大能量损失, 从而降低器件开路电压及电池整体性能 ${ }^{[26]}$. 并且 PEDOT:PSS 的亲水性以及弱酸性会影响钙钛矿太阳能 电池的稳定性 ${ }^{[27,28]}$.

因此, 开发高效率有机小分子空穴传输材料具有重 大意义. 首先, 有机小分子空穴传输层普遍具有较好的
疏水性, 可保护钻钛矿层免受水汽的侵蚀, 提高器件稳 定性 ${ }^{[29,30]}$. 其次，有机小分子材料分子量固定，批次差 异小, 结构更具多样性, 修饰位点丰富, 方便对其光电 性质进行调控，以定向设计与钙铁矿能级更匹配的空穴 传输材料, 进而提升器件开路电压. $\mathrm{Xu}$ 等 ${ }^{[31]}$ 报道了两种 基于三苯胺、联苯的线性 $\pi$ 共轭结构小分子空穴传输材 料 4,4'-bis(4-(di-p-toyl)aminostyryl)biphenyl (TPASBP)以 及 1,4'-bis(4-(di-p-toyl)aminostyryl)benzene (TPASB), 基 于两者的反向钙铁矿太阳能电池 PCE 分别为 $17.4 \%$ 和 $17.6 \%$. Wang 等 ${ }^{[32]}$ 报道了另一种 $\pi$ 共轭小分子材料 4,4'-cyclohexylidenebis[ $N, N$-bis(4-methylphenyl) benzeneamine] (TAPC), 其反向钙钛矿太阳能电池可获得高达 $18.8 \%$ 的 PCE. TAPC 的疏水性有效地改善了上层钻钣矿 薄膜的质量, 使得晶体尺寸变大, 未反应的 $\mathrm{PbI}_{2}$ 也因此 减少, 从而提升了钲钛矿太阳能电池稳定性. Chen 等 ${ }^{[33]}$ 设计出一种基于三聚狮和二苯胺, 结构上完全共轭的刚 性平面型小分子 Trux-OMeTAD, 这种分子具有高空穴 迁移率以及钙钛矿活性层所需的表面能. 其器件光电转 化效率达 $18.6 \%$, 且几乎无迟滞效应. $\mathrm{Li}$ 等 ${ }^{[34]}$ 合成出两 种以硅为核, 分别以三苯胺和二苯胺为共轭臂的 $\mathrm{X}$ 型小 分子空穴传输材料 Si-OMeTPA 和 SiTP-OMeTPA, 掺杂 条件下的反向器件可获得 $19.0 \%$ 的 PCE. 总体而言, 目 前在反向器件领域, 关于有机小分子空穴传输材料的报 道相对较少.

三苯胺(TPA)是空穴传输材料中常用的结构单元, 它具有较强的给电子能力, 其非平面的分子构型, 可抑 制分子聚集, 形成均一、光滑且形貌稳定的薄膜 ${ }^{[35,36]}$. 同时引入受体单元可对 HOMO 能级实现定向调控, 已 有文献报道具有 D-A 型分子结构的空穴传输材料可获 得优异的钙钛矿太阳能电池性能 ${ }^{[37,38]}$. 本文基于三苯胺 单元, 通过引入不同的给受体基团调控分子内电荷转移 能力, 设计合成了三种 $D-\pi-A-\pi-D$ 型有机小分子空穴传 输材料, 分别以三苯胺或甲氧基取代三苯胺为给体, 苯 环为共轭 $\pi$ 桥, 羰基或双氧基乙烯基为受体. 三个化合 物 1-T、1-OT 以及 1-OTCN 的分子结构如图式 1 所示. 在非掺杂情况下, 以这三种材料为空穴传输层制备了反 向钙钠矿太阳能电池, 器件结果表明, 基于 1-OTCN 材 料的器件 PCE 最高, 达到 $16.8 \%$, 并且其器件水氧稳定 性也优于传统空穴传输材料 PEDOT:PSS. 


\section{2 结果与讨论}

\section{1 有机小分子空穴传输材料的合成}

有机小分子空穴传输材料 1-T、1-OT 及 1-OTCN 的合成路线如图式 1 所示，中间产物合成路线见图式 S1 (见 Supporting Information). 将二苯甲酮与(甲氧基)三苯 胺硼酸酯进行 Suzuki 偶联反应获得产物 1-T 和 1-OT, 1-OT 与丙二腈经脱水反应获得材料 1-OTCN, 目标产 物均经过核磁、质谱以及元素分析的验证.

\section{2 热稳定性}

通过热重分析仪以及差示扫描量热仪分别对三个 材料的分解温度 ( $T_{\mathrm{d}}$, 定义为失重 $5 \mathrm{wt} \%$ 时的温度)及玻 璃化温度 $\left(T_{\mathrm{g}}\right)$ 进行测试, 结果如图 1 所示, 对应具体数值 列于表 1 中. 从图 $1 \mathrm{a}$ 可知三个材料均具有较好的热稳定
性， 1-T 分解温度最高为 $457{ }^{\circ} \mathrm{C}$, 甲氧基的引入使得化 合物 1-OT 分解温度 $\left(431{ }^{\circ} \mathrm{C}\right)$ 略微下降. 1-OTCN 玻璃化 温度 $\left(125{ }^{\circ} \mathrm{C}\right)$ 高于 1-T $\left(105{ }^{\circ} \mathrm{C}\right)$ 及 1-OT $\left(104{ }^{\circ} \mathrm{C}\right)$, 说明 双氧基的引入有利于提升材料玻璃化温度，使得膜形貌 更稳定，避免器件制备过程中产生相变 ${ }^{[39]}$, 有利于器件 稳定性的提升. 同时，玻璃化温度高说明材料结晶性差， 呈现出无定形态，有利于形成均一薄膜，便于后期钙钛 矿层的旋涂.

\section{3 光学性能}

采用紫外-可见(UV-Vis)吸收光谱仪和苂光光谱仪 对三种材料的吸收以及发射光谱进行测试. 固体薄膜状 态下的紫外-可见吸收和荧光发射光谱图如 2a 所示, 对 应的吸收和发射峰列于表 1 中. 三个化合物均表现出两 个主要吸收光谱带, 其中位于高能量区(300 $\mathrm{nm}$ 附近)的<smiles>[R]c1ccc(N(c2ccc([R])cc2)c2ccc(-c3ccc(C(=O)c4ccc(-c5ccc(N(c6ccc([R])cc6)c6ccc([R])cc6)cc5)cc4)cc3)cc2)cc1</smiles><smiles>COc1ccc(N(c2ccc(OC)cc2)c2ccc(-c3ccc(C(=O)c4ccc(-c5ccc(N(c6ccc(OC)cc6)c6ccc(OC)cc6)cc5)cc4)cc3)cc2)cc1</smiles>

图式 1 有机小分子空穴传输材料 1-T, 1-OT 和 1-OTCN 的分子结构及合成路线

Scheme 1 Chemical structures and synthesis of 1-T, 1-OT and 1-OTCN 

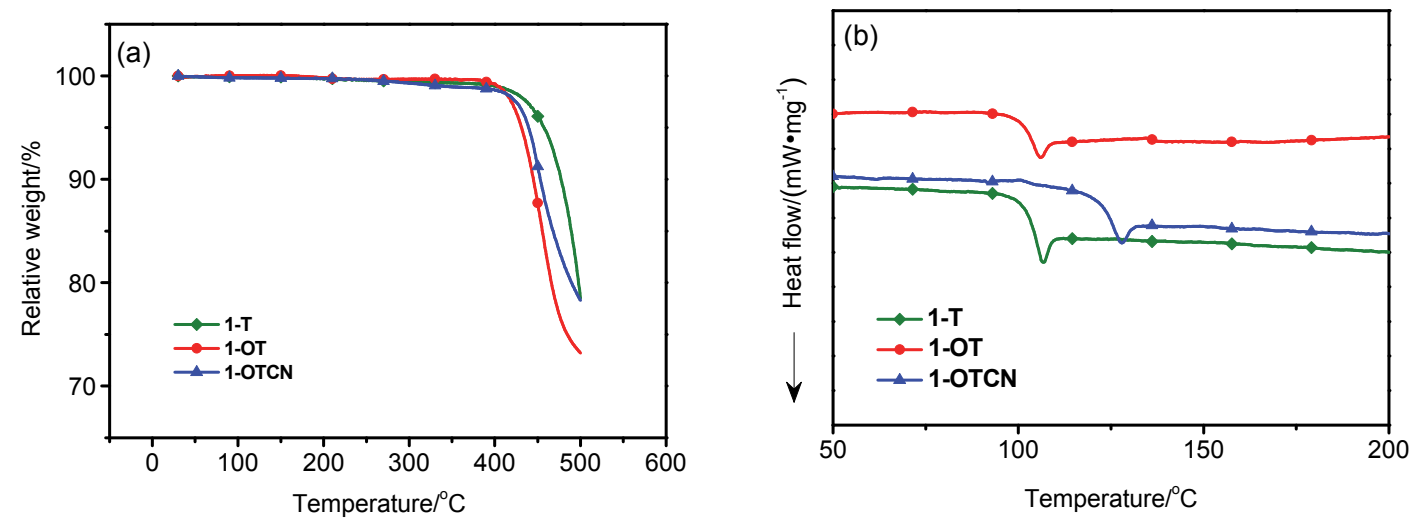

图 1 有机小分子空穴传输材料的(a)TGA 和(b)DSC 曲线

Figure 1 (a) TGA and (b) DSC curves of organic small molecular hole transporting materials
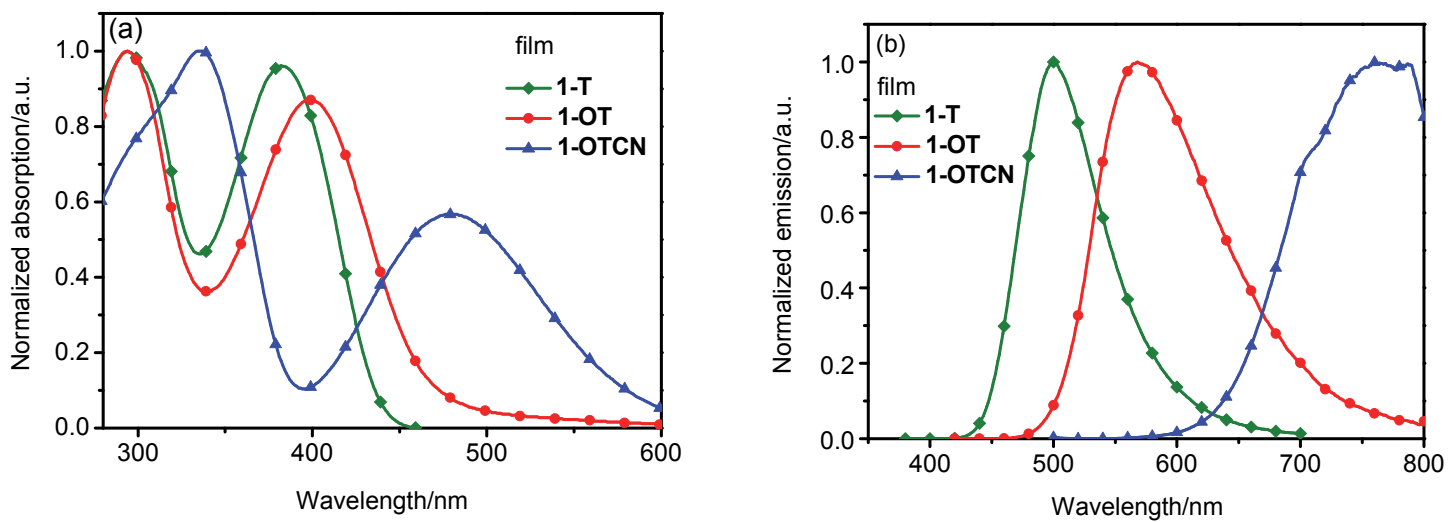

图 2 有机小分子空穴传输材料薄膜的(a)紫外-可见吸收和(b)苂光发射曲线

Figure 2 (a) UV-Vis absorption and (b) photoluminescence spectra of organic small molecular hole transporting materials

表 1 有机小分子空穴传输材料的热稳定性、光学和电化学性质

Table 1 Thermal stability, optical and electrochemical properties of organic small molecular hole transporting materials

\begin{tabular}{lcccccccccc}
\hline HTMs & $T_{\mathrm{g}} /{ }^{\circ} \mathrm{C}$ & $T_{\mathrm{d}} /{ }^{\circ} \mathrm{C}$ & $\lambda_{\mathrm{abs}}{ }^{a} / \mathrm{nm}$ & $\lambda_{\mathrm{em}}{ }^{a} / \mathrm{nm}$ & $\lambda_{\mathrm{abs}}{ }^{b} / \mathrm{nm}$ & $\lambda_{\mathrm{em}}{ }^{b} / \mathrm{nm}$ & $\lambda_{\text {onset }} / \mathrm{nm}$ & $E_{\mathrm{g}}{ }^{c} / \mathrm{eV}$ & $E_{\text {HOMO }} / \mathrm{eV}$ & $E_{\mathrm{LUMO}}{ }^{e} / \mathrm{eV}$ \\
\hline 1-T & 105 & 457 & 291,377 & 459 & 294,382 & 500 & 433 & 2.86 & -5.21 & -2.35 \\
1-OT & 104 & 431 & 293,393 & 507 & 294,401 & 568 & 464 & 2.67 & -4.91 & -2.24 \\
1-OTCN & 125 & 439 & 330,464 & 672 & 337,483 & 761 & 561 & 2.21 & -4.96 & -2.75 \\
\hline
\end{tabular}

${ }^{a}$ Absorption and emission peak in toluene solution; ${ }^{b}$ Absorption and emission peak in thin film; ${ }^{c} E_{\mathrm{g}}$ was calculated from the absorption edge in thin film, $E_{\mathrm{g}}=$ $1240 / \lambda_{\text {onset }} ;{ }^{d} \mathrm{HOMO}$ was measured by cyclic voltammograms; ${ }^{e}$ LUMO was calculated from $E_{\mathrm{LUMO}}=-\left(-E_{\mathrm{HOMO}}-E_{\mathrm{g}}\right)$.

吸收主要来源于分子骨架的 $\pi-\pi *$ 和三苯胺 $\mathrm{N}$ 原子上 $\mathrm{n}-\pi^{*}$ 的跃迁, 而长波长处吸收峰则归属于分子内电子给 体与受体之间电荷转移(Intramolecular Charge Transfer, ICT)跃迁的吸收. 较之 1-T, 1-OT 位于长波长处的吸收 光谱发生红移，说明强给电子基团甲氧基的引入增强了 ICT 跃迁的吸收. 1-OTCN 吸收光谱红移更加明显, 其 中, 高能量区 $330 \mathrm{~nm}$ 处出现的新吸收峰可能为双氧基 乙烯基的 $\pi-\pi *$ 跃迁吸收, 而在 $400 \sim 600 \mathrm{~nm}$ 范围内的宽 吸收峰, 则是因为额外给电子基团甲氧基和强拉电子单 元双氧基乙烯基的双重引入, 大大增强了 ICT 所致. 图 $\mathrm{S} 1$ 为三个材料在甲苯溶液中的吸收及发射光谱, 相比
1-OT 和 1-T, 1-OTCN 在固体状态下的吸收红移更明显, 表明 1-OTCN 在薄膜状态下具有较强的分子间相互作 用力. 从发射光谱可知, 1-OTCN 在固体状态下的斯托 克斯位移(278 nm)远大于另外两种材料(1-T: $118 \mathrm{~nm}$, 1-OT: $167 \mathrm{~nm})$, 说明当 1-OTCN 被激发时, 分子几何结 构发生了较大变化 ${ }^{[40]}$.

\section{4 理论计算}

采用密度泛函理论(Density Functional Theory, DFT) 计算的方法优化目标小分子的几何构型, 并对分子轨道 电子云密度分布，最高占有分子轨道(Highest Occupied Molecular Orbital, HOMO) 以及最低未占有分子轨道 
(Lowest Unoccupied Molecular Orbital, LUMO)能级进行 初步估算. 能级计算结果列于表 1 中, 表 S1 所示为优化 的分子几何构型以及电子云密度分布图. 三种材料的 HOMO 电子云主要分布在具有给电子性能的(甲氧基) 三苯胺, LUMO 电子云主要集中在具有吸电子能力的羰 基(或双㲵基乙烯基), HOMO 和 LUMO 电子云在苯环 $\pi$ 桥上有所重叠, 表明这种 $D-\pi-A-\pi-\mathrm{D}$ 结构有利于分子内 电荷转移.

\section{5 电化学性能}

采用循环伏安法对材料的电化学性质进行测试. 将 化合物溶于 $10 \mathrm{~mL}$ 含 $0.1 \mathrm{~mol} \cdot \mathrm{L}^{-1}$ 四丁基六氟磷酸胺 $\left(\mathrm{Bu}_{4} \mathrm{NPF}_{6}\right)$ 的二氯甲烷中, 插入标准三电极 $\left(\mathrm{Ag} / \mathrm{Ag}^{+}\right.$作为 参比电极, $\mathrm{Pt}$ 丝为对电极, $\mathrm{Pt}$ 为工作电极). 鼓入氮气除 氧半小时后开始测试. 三个化合物均表现出可逆的电化 学氧化行为及不可测得的还原行为. 图 3 所示为已扣除 内标二茂铁氧化电位值的 $\mathrm{CV}$ 曲线, 由起始氧化电位 $\left(E_{\text {ox.onset }}\right)$ 值以及公式: $E_{\mathrm{HOMO}}=-\left(4.8+E_{\text {ox.onset }}\right)$, 计算出 $\mathrm{HOMO}$ 能级值, 之后根据薄膜中吸收光谱得到的光学 带隙 $E_{\mathrm{g}}$, 再根据公式 $E_{\mathrm{LUMO}}=-\left(-E_{\mathrm{HOMO}}-E_{\mathrm{g}}\right)$, 得出 LUMO 值. 引入具有给电子能力的甲氧基会大大提升 化合物的 HOMO 能级, 例如 1-OT 及 1-OTCN 的 HOMO 能级分别为 -4.91 和 $-4.96 \mathrm{eV}$, 高于 $\mathbf{1 - T}(-5.21 \mathrm{eV})$. 而引入强吸电子能力的双氰基则会较大幅度地降低材 料的 LUMO 能级, 例如, 1-OTCN 的 LUMO 值( -2.75 $\mathrm{eV})$ 明显低于 1-T $(-2.35 \mathrm{eV})$ 和 1-OT $(-2.24 \mathrm{eV})$. 从表 1 可以看出, 实验测试与理论计算结果所得能级趋势一 致.

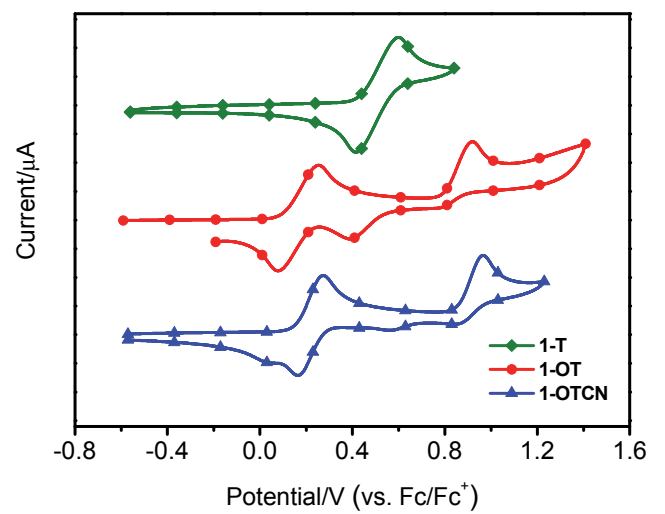

图 3 有机小分子空穴传输材料的循环伏安曲线

Figure 3 CV curves of organic small molecular hole transporting materials

\section{6 表面性能}

钙钛矿材料易受水的侵蚀而分解, 因此具有疏水性 质的空穴传输材料可以有效隔绝环境中的水, 从而有利 于钙钛矿太阳能电池的稳定性. 我们通过测试材料与水 的接触角来研究其表面性质. 测试结果如图 S2 所示, 1-T、1-OT 及 1-OTCN 与水的接触角分别为 $103.7^{\circ} 、 97.9^{\circ}$
和 $58.0^{\circ}$, 远远大于钙钛矿太阳能电池中常用的空穴传 输材料 PEDOT:PSS $\left(20.5^{\circ}\right)$. 随着甲氧基和双氰基这些 极性基团的引入，材料疏水性有所降低，但仍远大于 PEDOT:PSS. 因此将这三种材料作为反向器件的空穴 传输层, 会提升电池器件稳定性. 其次, 已有文献报道 适当降低润湿性可以促进钙钛矿晶粒生长, 有利于电荷 转移, 从而提高光伏性能. 润湿性过差则会导致上层钙 钛矿溶液铺展不佳, 进而影响膜形貌, 不利于光伏性能 提升 ${ }^{[41,42]}$.

\section{7 光伏特性}

将 1-T、1-OT 以及 1-OTCN 作为空穴传输层，制备 反向钲钛矿太阳能电池: ITO/HTM/ $\mathrm{MAPbI}_{3} / \mathrm{PC}_{61} \mathrm{BM} /$ $\mathrm{C}_{60} / \mathrm{BCP} / \mathrm{Ag}$ (如图 4 所示), 由此探究这三个材料的光伏 性能. 化合物的疏水性使得钙钛矿前驱体溶液在空穴传 输层上的铺展性不理想. 为了获得能完全覆盖空穴传输 层的钙钛矿薄膜, 在前驱体溶液旋涂前需采用极性溶剂 (DMF)润洗. 同时也一并制备了基于传统空穴传输材料 PEDOT:PSS 的器件, 用于对比研究本文中新设计合成 的小分子空穴传输材料. 在 AM1.5G, $100 \mathrm{~mW} \cdot \mathrm{cm}^{-2}$ 的光 强条件下对器件性能进行表征, 结果如图 5a 所示, 相应 的器件参数列于表 2 . 在相同器件制作水平下, 基于 1-T、1-OT 以及 1-OTCN 的器件开路电压 $\left(V_{\mathrm{OC}}\right)$ 均在 1.07 $\mathrm{V}$ 以上, 远大于 PEDOT:PSS $(0.89 \mathrm{~V})$. 其中, 不含任何 修饰基团的 1-T 化合物, 器件的最大 PCE、开路电压 $\left(V_{\mathrm{OC}}\right)$ 、短路电流密度 $\left(J_{\mathrm{SC}}\right)$ 和填充因子 $(\mathrm{FF})$ 分别为 $13.0 \%$, $1.06 \mathrm{~V}, 18.89 \mathrm{~mA} \cdot \mathrm{cm}^{-2}$ 和 $62 \%$. 通过甲氧基对 1-T 进行 改性后, 虽然基于 1-OT 器件 $J_{\mathrm{SC}}$ 有所下降, 但填充因子 提升明显, 因而器件 PCE 提升至 $14.4 \%$. 将同时含有甲 氧基和双氰基的 1-OTCN 作为空穴传输材料, 电池器件 的最佳 PCE 为 $16.8 \%$, 在保留较高 $\mathrm{FF}(78 \%)$ 的同时, $J_{\mathrm{SC}}$ 也获得较大提升 $\left(20.13 \mathrm{~mA} \cdot \mathrm{cm}^{-2}\right)$, 后续也通过其它相 关测试对基于各材料器件性能的差异进行探究. 图 S3 所示为 1-OTCN 最佳器件与基于 PEDOT:PSS 器件正反 扫 $J \sim V$ 曲线滞后性的对比, 发现基于 1-OTCN 器件的 滞后性更小. 为了验证电流密度 $(J)$-电压 $(V)$ 特性曲线所

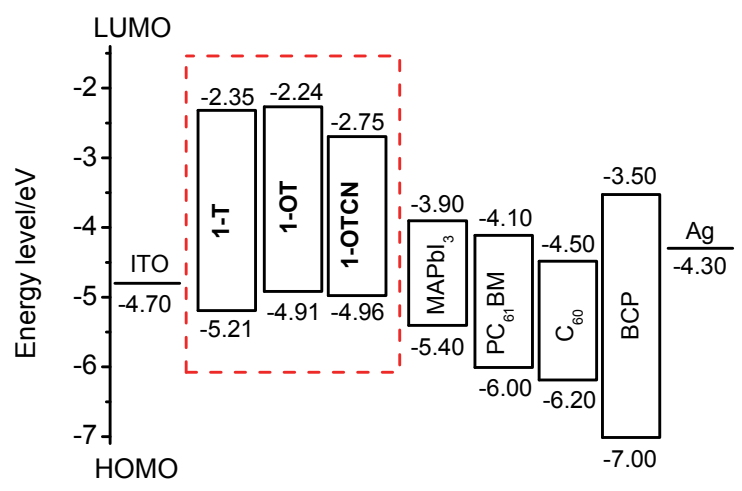

图 4 反向钙铁矿太阳能电池结构及功能层能级

Figure 4 The structure of inverted perovskite solar cells and energy levels of function layers 
得短路电流密度值的准确性, 对器件的外量子效率曲线 进行了测试, 并计算出相应积分电流密度, 如图 $5 \mathrm{~b}$ 所 示, 具体数据列于表 2 . 两种方法获得的数据相近, 证 实了器件测试结果的可靠性.

\section{8 电荷传输性能}

通过空穴迁移率以及界面电荷跃迁、复合情况, 来 探究三个化合物器件性能产生差异的原因. 采用空间电 荷限制电流(Space Charge Limited Current, SCLC)的方 法 $^{[43]}$, 通过制备单空穴器件(ITO/PEDOT:PSS/有机小分 子空穴传输材料/Au)对材料的空穴迁移率进行测试. 电 流密度平方根 $\left(J_{1 / 2}\right)$ 与电压 $(V)$ 特性曲线如图 $\mathrm{S} 4$ 所示, 对

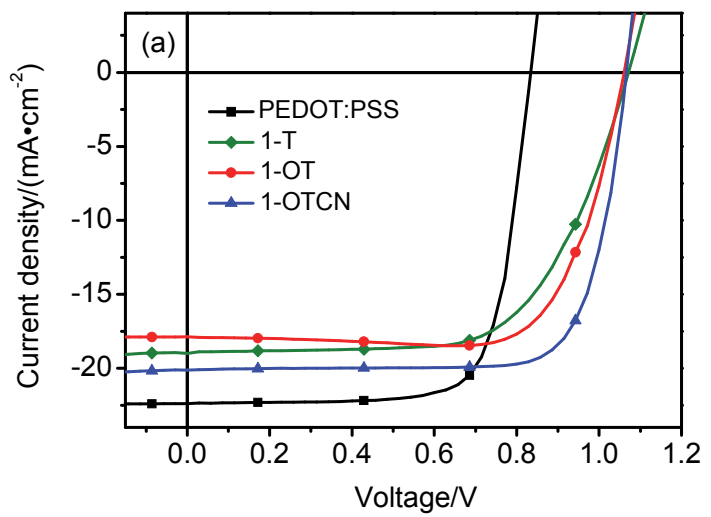

应空穴迁移率值列于表 S3 中, 1-T、1-OT 与 1-OTCN 的空穴迁移率分别为 $1.3 \times 10^{-5} 、 6.1 \times 10^{-5}$ 和 $3.2 \times 10^{-5}$ $\mathrm{cm}^{2} \cdot \mathrm{V}^{-1} \cdot \mathrm{s}^{-1}$ ，大小处于同一数量级，因此空穴迁移率不 是导致器件短路电流密度产生差异的主要原因. 进一步 采用稳态光致发光以及时间分辨光致发光 ( T i m e Resolved Photoluminescence, TRPL)探测电荷在钙钛矿 与空穴传输层界面的跃迁、收集及复合情况. 测试结果 如图 $6 \mathrm{a}$ 和图 $6 \mathrm{~b}$ 所示, 空穴传输层有效猝灭了钙钛矿的 发光, 尤其是 1-OTCN 材料对钻钛矿发光猝灭程度最 大，而空穴迁移率最高的 1-OT 猝灭程度最低. 通过瞬 态苂光测试得到的具体寿命值列于表 S3 中. 其中, 1-T

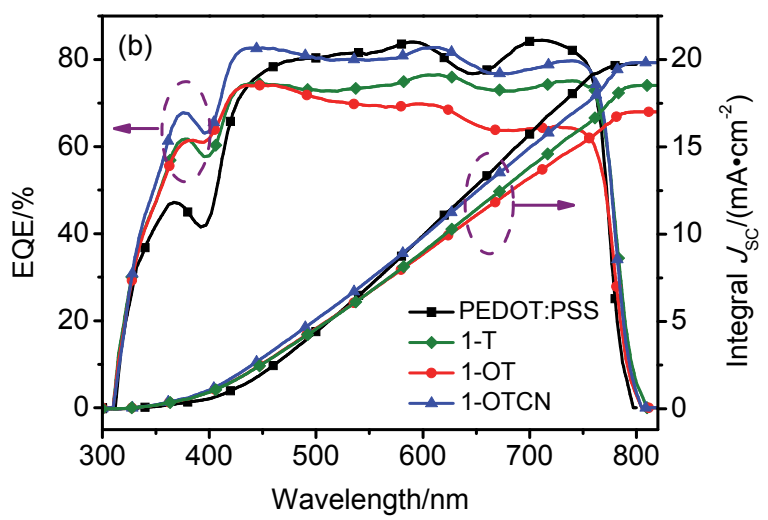

图 5 基于不同空穴传输材料的钻钛矿太阳能电池(a) $J \sim V$ 曲线和(b)EQE 及积分电流密度曲线

Figure 5 (a) $J \sim V$; (b) EQE and integral current density curves of perovskite solar cells based on different HTLs

表 2 基于不同空穴传输层的电池器件性能参数

Table 2 Photovoltaic parameters of perovskite solar cells based on different HTLs

\begin{tabular}{|c|c|c|c|c|c|}
\hline HTMs & $V_{\mathrm{OC}} / \mathrm{V}$ & $J_{\mathrm{Sd}} /\left(\mathrm{mA} \cdot \mathrm{cm}^{-2}\right)$ & $J_{\mathrm{SC}, \mathrm{cal}} /\left(\mathrm{mA} \cdot \mathrm{cm}^{-2}\right)$ & $\mathrm{FF} / \%$ & $\left(\mathrm{PCE}_{\max } / \mathrm{PCE}_{\mathrm{ave}}^{a}\right) / \%$ \\
\hline PEDOT:PSS & $0.83 \pm 0.00(0.83)$ & $20.58 \pm 1.19(20.74)$ & 19.85 & $73 \pm 2(75)$ & $13.0 / 12.6$ \\
\hline 1-OT & $1.06 \pm 0.02(1.08)$ & $17.05 \pm 0.86(17.21)$ & 17.01 & $76 \pm 3(77)$ & $14.4 / 14.0$ \\
\hline 1-OTCN & $1.07 \pm 0.02(1.09)$ & $20.00 \pm 0.19(20.13)$ & 19.83 & $77 \pm 1(78)$ & $16.8 / 16.5$ \\
\hline
\end{tabular}

${ }^{a}$ The average PCE values were calculated from over 10 devices for each condition.
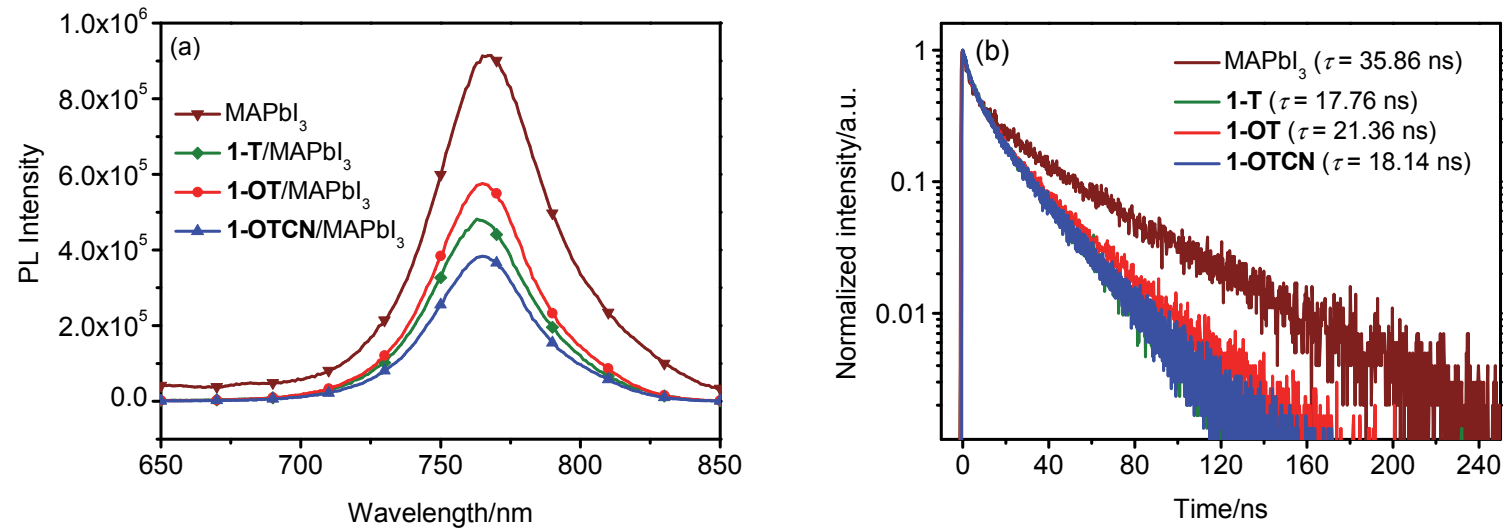

图 6 基于石英片/钻钛矿及石英片/HTL/钻钛矿的(a)稳态光致发光曲线和(b)时间分辨光致发光衰减曲线

Figure 6 (a) Steady state photoluminescence (PL) spectrum and (b) time-resolved PL decay of devices based on the glass/perovskite and glass/HTL/perovskite 
与 1-OTCN 电荷衰减寿命相近，分别为 17.76 和 18.14 $\mathrm{ns}$, 而 1-OT 相对较高, 为 $21.36 \mathrm{~ns}$. 综合以上因素, 可 以得出 1-OTCN 与钲钛矿之间的电荷跃迁及收集最为 有效, 且辐射复合得到更为有效的抑制，因而 1-OTCN 器件可以获得较高 $J_{\mathrm{SC}}$.

\section{9 膜形貌}

钲钛矿膜形貌对器件性能存在较大影响, 因此, 采 用原子力显微镜(Atomic Force Microscopy, AFM)以及扫 描电镜(Scanning Electron Microscopy, SEM)对钙钛矿表 面粗粘度、结晶情况进行表征, 结果如图 7 所示. 从 AFM 图可知, 钙钛矿在三种小分子空穴传输层上均可 形成光滑的薄膜, 粗楉度 (1-T, 1-OT 与 1-OTCN 分别为 $13.79,9.42$ 和 $10.75 \mathrm{~nm})$ 与基于 PEDOT:PSS (9.56 nm)的 钙钛矿膜相近. 光滑的钙钛矿膜有利于与上层界面形成 良好接触, 便于电荷传输. 从 SEM 可以看出, 钙钛矿膜 可完全覆盖住有机小分子空穴传输层. 另外, 基于 PEDOT:PSS 的钙钛矿薄膜有较多孔洞, 沉积于小分子 空穴传输材料的钙钛矿薄膜缺陷相对较少, 其中 1-OTCN 上的钙钛矿晶体尺寸最为均匀, 不易于发生电 荷复合. 因此采用 1-OTCN 作为空穴传输层的器件具有 较高 $J_{\mathrm{SC}}$ 以及 $\mathrm{FF}$.

\subsection{0 器件稳定性}

将基于 PEDOT:PSS 以及 1-OTCN 的未封装钙钛矿 太阳能电池避光放置于空气中(温度: $20 \pm 5{ }^{\circ} \mathrm{C}$, 相对湿 度: $30 \% \pm 5 \%$ ), 对比两种电池器件在空气中的稳定性. 从图 8 可以看出, $4 \mathrm{~d}$ 后, 基于 PEDOT:PSS 的器件 PCE 只有初始值的 50\%, 而含 1-OTCN 材料的器件效率 $10 \mathrm{~d}$ 后仍能达到原来的 $75 \%$, 具有较好的水氧稳定性. 基于 1-OTCN 材料的器件各项参数衰减曲线均呈现平稳走 向. 因此, 空穴传输材料的疏水性质对于钻钛矿太阳能 电池的稳定性起到关键作用.
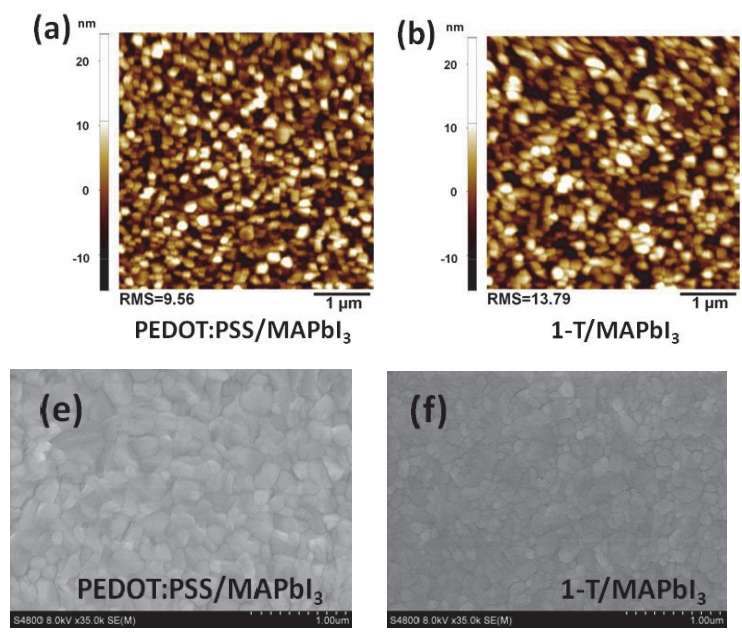

\section{3 结论}

本文设计合成了三种 $D-\pi-A-\pi-D$ 结构的有机小分子 空穴传输材料 1-T、1-OT 和 1-OTCN, 探究引入不同给 受体基团对空穴传输材料各项性能的影响. 相比 1-T, 以给电子甲氧基封端三苯胺的 1-OT, HOMO 能级上升, 空穴迁移率更高. 在 1-OT 的结构基础上, 进一步引入 具有强拉电子能力的双氰基，降低了 LUMO 能级，增强 了分子内 D-A 相互作用, 得到了高效空穴传输材料 1-OTCN. 将三种小分子空穴传输材料在非掺杂情况下 运用于反向钲钛矿太阳能电池, 基于 1-OTCN 的电池器 件性能最佳, $\mathrm{PCE}$ 最高为 $16.8 \%, V_{\mathrm{OC}}$ 为 $1.09 \mathrm{~V}, J_{\mathrm{SC}}$ 为 $20.13 \mathrm{~mA} \cdot \mathrm{cm}^{-2}, \mathrm{FF}$ 为 $78 \%$. 同一器件制备条件下以 PEDOT:PSS 为空穴传输层的电池器件 PCE 仅为 $13.0 \%$. 通过 PL 以及 TRPL 实验结果, 发现 1-OTCN 与钙钛矿 之间发生了更为有效的电荷跃迁及收集，电荷复合也相 对较少. 较之 1-T 和 1-OT, 沉积于 1-OTCN 的钻钛矿膜 晶体尺寸大小更均匀, 缺陷相对较少, 因此电池器件的 $J_{\mathrm{SC}}$ 以及 $\mathrm{FF}$ 较高. 另外, 有机小分子空穴传输材料较强 的疏水性质使得电池器件的水氧稳定性远大于以 PEDOT:PSS 为空穴传输层的器件. 本文工作凸显了 $D-\pi-A-\pi-D$ 型有机小分子空穴传输材料在非掺杂、高效、 稳定的反向钙钛矿太阳能电池中的应用潜能. 最后, 设 计分子结构简单、合成方法简便的有机小分子空穴传输 材料, 有助于降低成本, 进一步推动钙钛矿太阳能电池 早日实现商业化.

\section{4 实验部分}

\section{1 试剂与仪器}

药品溶剂均来自于市售, 如无特别说明则直接使 用. 无水甲苯经金属钠处理，以二苯甲酮作指示剂蒸馏 得到.
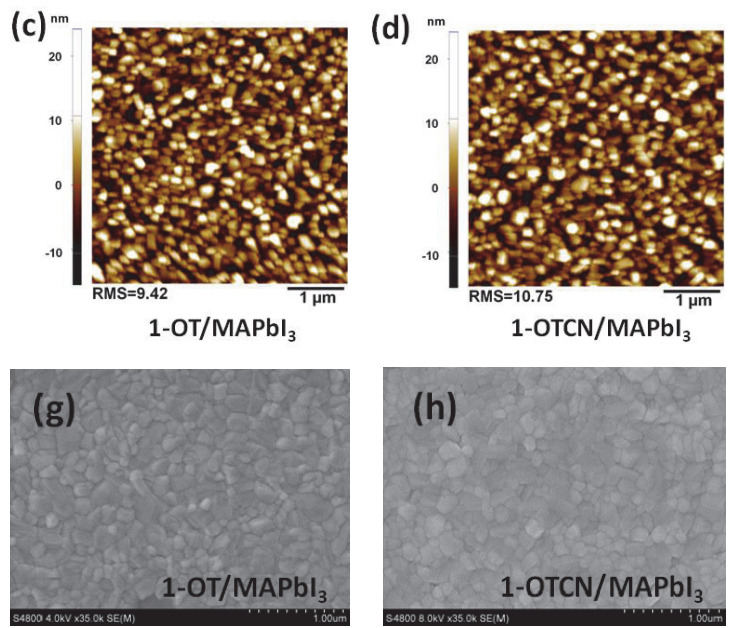

图 7 ITO/PEDOT:PSS/MAPbI 3 , ITO/1-T/MAPbI, $\mathrm{ITO} / \mathbf{1 - O T} / \mathrm{MAPbI}_{3}$ 和 ITO/1-OTCN/MAPbI ${ }_{3}$ 表面 $\mathrm{AFM}$ 高度图(a $\sim \mathrm{d}$ )以及 $\mathrm{SEM}$ 图(e $\sim \mathrm{h}$ ) Figure 7 Top view AFM height images $(\mathrm{a} \sim \mathrm{d})$ and SEM images $(\mathrm{e} \sim \mathrm{h})$ of ITO/PEDOT:PSS/MAPbI ${ }_{3}, \mathrm{ITO} / \mathbf{1}-\mathrm{T} / \mathrm{MAPbI}{ }_{3}, \mathrm{ITO} / \mathbf{1 - O T} / \mathrm{MAPbI}{ }_{3}$ and ITO/1-OTCN/MAPbI ${ }_{3}$ 


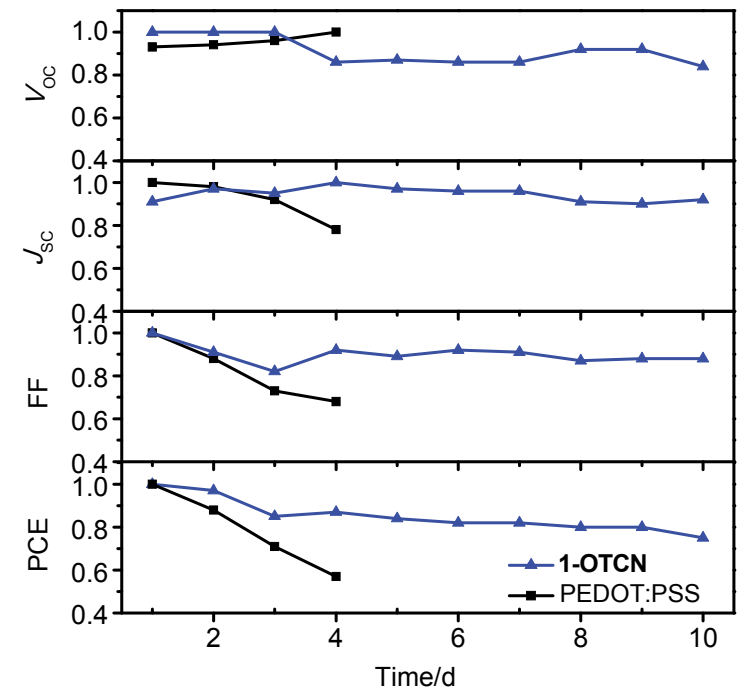

图 8 基于 PEDOT:PSS 以及 1-OTCN 的钲钛矿太阳能电池器件稳定 性

Figure 8 The stability of perovskite solar cells based on PEDOT:PSS and 1-OTCN

${ }^{1} \mathrm{H}$ NMR 谱用 Bruker DRX-400 型核磁共振谱仪在 $500 \mathrm{MHz}$ 测得(部分在 $300 \mathrm{MHz}$ ), $\mathrm{CDCl}_{3}$ 为溶剂, $\mathrm{TMS}$ 为 内标. MALDI-TOF MS 由 Bruker Daltonics Inc. BIFLEX III 测定. 元素分析由 Varia III 型元素分析仪测得. $J \sim V$ 曲线采用 Keithley 2400 Source Measure Unit 测试, 光源 为太阳光模拟器 (Enlitech SS-F5-3A). EQE 测试采用 QE-R3-011 太阳能电池光谱响应测量系统(Enli Technology, Taiwan).

\section{2 合成}

化合物 1 的合成: 先将 $\mathrm{CuI}\left(0.19 \mathrm{~g}, 1 \mathrm{mmol} \cdot \mathrm{L}^{-1}\right)$ 与 1,10 - 菲罗啉 $\left(0.27 \mathrm{~g}, 1.5 \mathrm{mmol} \cdot \mathrm{L}^{-1}\right)$ 以及 $10 \mathrm{~mL}$ 无水甲苯 加至 $50 \mathrm{~mL}$ 的两口烧瓶内搅拌反应 $0.5 \mathrm{~h}$, 之后加入对溴 碘苯 $\left(3.39 \mathrm{~g}, 12 \mathrm{mmol} \cdot \mathrm{L}^{-1}\right)$, 甲氧基二苯胺 $(2.29 \mathrm{~g}, 10$ $\left.\mathrm{mmol} \cdot \mathrm{L}^{-1}\right)$ 以及 $\mathrm{KOH}\left(4.49 \mathrm{~g}, 80 \mathrm{mmol} \cdot \mathrm{L}^{-1}\right)$ 至烧瓶中, 继 续加入无水甲苯 $15 \mathrm{~mL}$, 抽换气三次, 在氮气氛围下以 $115{ }^{\circ} \mathrm{C}$ 加热摚拌 $24 \mathrm{~h}$. 反应结束后冷却至常温, 用饱和 食盐水洗涤反应溶液, 使用二氯甲烷 $(20 \mathrm{~mL} \times 3)$ 萃取产 物. 粗产物用 $V(\mathrm{DCM}): V(\mathrm{PE})=1: 2$ 洗脱剂进行硅胶 色谱纯化, 得到白色固体投至下一步反应.

化合物 2 的合成: 合成反应条件同三苯胺硼酸酯, 之后采用 $V(\mathrm{DCM}): V(\mathrm{PE})=1: 1$ 作为洗脱剂进行硅胶 色谱纯化, 最后通过 DCM 和乙醇进行重结晶得到白色 固体. ${ }^{1} \mathrm{H}$ NMR $\left(\mathrm{CDCl}_{3}, 300 \mathrm{MHz}\right) \delta: 8.07(\mathrm{~d}, J=8.1 \mathrm{~Hz}$, $2 \mathrm{H}), 7.45(\mathrm{~d}, J=9.0 \mathrm{~Hz}, 2 \mathrm{H}), 7.35(\mathrm{~d}, J=8.1 \mathrm{~Hz}, 2 \mathrm{H})$, $6.92 \sim 6.97(\mathrm{~m}, 4 \mathrm{H}), 6.25(\mathrm{~d}, J=7.2 \mathrm{~Hz}, 2 \mathrm{H}), 1.69(\mathrm{~s}, 6 \mathrm{H})$, $1.40(\mathrm{~s}, 12 \mathrm{H})$.

化合物 3 的合成: 称取化合物三苯胺 $(10.00 \mathrm{~g}, 40.76$ $\mathrm{mmol} \cdot \mathrm{L}^{-1}$ ), 量取 $80 \mathrm{~mL}$ 氯仿加至洁净的圆底烧瓶中, 使三苯胺溶解, 置于冰浴避光, 随后分次加入 NBS $\left(7.26 \mathrm{~g}, 40.76 \mathrm{mmol} \cdot \mathrm{L}^{-1}\right)$ 室温反应过夜. 反应结束加水
淬灭反应，用二氯甲烷 (Dichloromethane，DCM)(25 $\mathrm{mL} \times 3)$ 萃取。产物溶于有机相, 有机相采用无水 $\mathrm{MgSO}_{4}$ 干燥, 之后抽滤, 在减压条件下旋蒸出有机溶 剂. 采用乙醇重结晶, 抽滤得白色固体(产率 $90 \%$ ), 直 接投下一步反应.

化合物 4 的合成: 将化合物 $\mathbf{1}(5.0 \mathrm{~g}, 15.42 \mathrm{mmol} \cdot$ $\left.\mathrm{L}^{-1}\right)$, 联硼酸频哪醇酯 $\left(4.7 \mathrm{~g}, 18.50 \mathrm{mmol} \cdot \mathrm{L}^{-1}\right), \mathrm{PdCl}_{2}$ $(\mathrm{dppf})_{2}\left(0.112 \mathrm{~g}, 0.154 \mathrm{mmol} \cdot \mathrm{L}^{-1}\right)$ 和乙酸钾 $(\mathrm{AcOK})(4.5$ $\mathrm{g}, 46.26 \mathrm{mmol} \cdot \mathrm{L}^{-1}$ )加入 $100 \mathrm{~mL}$ 两口圆底烧瓶中, 抽换 气三次. 在氮气氛围下, 将无水甲苯 $(60 \mathrm{~mL})$ 加入到上述 混合物中, $120{ }^{\circ} \mathrm{C}$ 加热并搅拌 $24 \mathrm{~h}$. 反应结束后加入水 淬灭反应, 并用二氯甲烷 $(20 \mathrm{~mL} \times 3)$ 萃取. 有机层用盐 水洗涤, 经 $\mathrm{MgSO}_{4}$ 干燥并过滤. 除去溶剂后, 通过使用 $V(\mathrm{DCM}): V(\mathrm{PE})=1: 2$ 洗脱剂进行硅胶色谱纯化, 最 后通过 DCM 和乙醇进行重结晶得到白色固体. ${ }^{1} \mathrm{H}$ NMR $\left(\mathrm{CDCl}_{3}, 500 \mathrm{MHz}\right) \delta: 7.66(\mathrm{~d}, J=8.5 \mathrm{~Hz}, 2 \mathrm{H}), 7.24(\mathrm{t}, J=$ $8.0 \mathrm{~Hz}, 4 \mathrm{H}), 7.10$ (d, $J=8.5 \mathrm{~Hz}, 4 \mathrm{H}), 7.03$ (t, $J=8.5 \mathrm{~Hz}$, $4 \mathrm{H}), 1.33(\mathrm{~s}, 12 \mathrm{H})$.

1-T 的合成: 将 4,4'二二溴二苯甲酮 $(1 \mathrm{~g}, 2.94 \mathrm{mmol}$ $\left.\mathrm{L}^{-1}\right)$, 三苯胺硼酸酯 $\left(3.28 \mathrm{~g}, 8.82 \mathrm{mmol} \cdot \mathrm{L}^{-1}\right)$ 和碳酸钾 $\left(3.25 \mathrm{~g}, 23.52 \mathrm{mmol} \cdot \mathrm{L}^{-1}\right)$ 加至 $50 \mathrm{~mL}$ 两口圆底烧瓶中, 随后将甲苯、乙醇以及去离子水按 $12: 8: 4 \mathrm{~mL}$ 混合投 入, 抽换气三次, 在氮气氛围下加入 $\mathrm{Pd}\left(\mathrm{PPh}_{3}\right)_{4}(10.74$ $\left.\mathrm{mg}, 9.30 \mu \mathrm{mol} \cdot \mathrm{L}^{-1}\right)$. 在氮气氛围下, $110{ }^{\circ} \mathrm{C}$ 加热回流并 搅拌反应 $20 \mathrm{~h}$, 冷却至室温. 反应结束后用饱和食盐水 洗涤, 并用二氯甲烷 $(20 \mathrm{~mL} \times 3)$ 萃取. 减压旋蒸除去溶 剂, 粗产物采用 $V(\mathrm{DCM}): V(\mathrm{PE})=2: 1$ 的洗脱剂进行 硅胶色谱纯化, 最后通过 DCM 和乙醇进行重结晶得到 黄色固体 1-T (1.18 g, 产率 60\%). ${ }^{1} \mathrm{H}$ NMR $\left(\mathrm{CDCl}_{3}, 500\right.$ MHz) $\delta$ : $7.90(\mathrm{~d}, J=8.0 \mathrm{~Hz}, 4 \mathrm{H}), 7.69(\mathrm{~d}, J=8.5 \mathrm{~Hz}, 4 \mathrm{H})$, 7.54 (d, $J=8.5 \mathrm{~Hz}, 4 \mathrm{H}), 7.29$ (t, $J=8.0 \mathrm{~Hz}, 8 \mathrm{H}), 7.16$ (d, $J$ $=8.5 \mathrm{~Hz}, 12 \mathrm{H}), 7.07(\mathrm{t}, J=7.5 \mathrm{~Hz}, 4 \mathrm{H}) ;{ }^{13} \mathrm{C} \mathrm{NMR}$ $\left(\mathrm{CDCl}_{3}, 75 \mathrm{MHz}\right) \delta: 148.1,147.4,144.5,135.9,133.3$, 130.7, 129.3, 127.9, 126.2, 124.7, 123.3, 77.4, 77.0, 76.5. MS (MALDI-TOF) calcd for $\mathrm{C}_{49} \mathrm{H}_{36} \mathrm{~N}_{2} \mathrm{O}[\mathrm{M}]^{+}$668.28; found 668.69. Anal. calcd for $\mathrm{C}_{49} \mathrm{H}_{36} \mathrm{~N}_{2} \mathrm{O}$ : C 87.99, H 5.43, N 4.19, O 2.39; found C 87.97, H 5.45, N 4.19, O 2.39.

1-OT 的合成: 1-OT 反应条件同上, 粗产物采用 $V(\mathrm{DCM}): V(\mathrm{PE})=2: 1$ 的洗脱剂进行硅胶色谱柱层析 纯化, 最后通过 DCM 和乙醇进行重结晶得到深黄色固 体粉末 1-OT (1.74 g, 产率 75\%). ${ }^{1} \mathrm{H}$ NMR $\left(\mathrm{CDCl}_{3}, 500\right.$ MHz) $\delta: 7.86(\mathrm{~d}, J=8.0 \mathrm{~Hz}, 4 \mathrm{H}), 7.65(\mathrm{~d}, J=8.0 \mathrm{~Hz}, 4 \mathrm{H})$, 7.47 (d, $J=8.5 \mathrm{~Hz}, 4 \mathrm{H}), 7.09$ (d, $J=8.5 \mathrm{~Hz}, 8 \mathrm{H}), 6.98$ (d, $J=9.0 \mathrm{~Hz}, 4 \mathrm{H}), 6.85$ (d, $J=9.0 \mathrm{~Hz}, 8 \mathrm{H}), 3.80(\mathrm{~s}, 12 \mathrm{H})$; ${ }^{13} \mathrm{C}$ NMR $\left(\mathrm{CDCl}_{3}, 75 \mathrm{MHz}\right) \delta: 156.2,149.0,144.7,140.5$, $135.6,131.2,130.7,127.7,126.9,125.9,120.2,114.8$, 77.4, 77.0, 76.5, 55.5. MS (MALDI-TOF) calcd for $\mathrm{C}_{53} \mathrm{H}_{44} \mathrm{~N}_{2} \mathrm{O}_{5}[\mathrm{M}]^{+} 788.33$; found 788.70. Anal. calcd for 
$\mathrm{C}_{53} \mathrm{H}_{44} \mathrm{~N}_{2} \mathrm{O}_{5}$ : C 80.69, H 5.62, N 3.55, O 10.14; found $\mathrm{C}$ $80.68, \mathrm{H} 5.63$, N 3.55, O 10.14.

1-OTCN 的合成 ${ }^{[44]}$ : 将 1-OT (500 mg, $0.63 \mathrm{mmol}$ • $\left.\mathrm{L}^{-1}\right)$, 丙二腈 $\left(50 \mathrm{mg}, 0.9 \mathrm{mmol} \cdot \mathrm{L}^{-1}\right)$ 加入 $25 \mathrm{~mL}$ 两口圆底 烧瓶中, 随后将 $20 \mathrm{~mL}$ 二氯甲烷倒入烧瓶中, 抽换气三 次, 在氮气氛围, $0{ }^{\circ} \mathrm{C}$ (冰浴)条件下加入 $\mathrm{TiCl}_{4}(357 \mathrm{mg}$, $\left.1.89 \mathrm{mmol} \cdot \mathrm{L}^{-1}\right)$, 之后保持冰浴反应 $0.5 \mathrm{~h}$. 然后加入吡 啶(151 mg, $1.89 \mathrm{mmol} \cdot \mathrm{L}^{-1}$ ) 继续反应 $0.5 \mathrm{~h}$. 最后将温度 升至 $60{ }^{\circ} \mathrm{C}$ 加热回流并搅拌反应 $12 \mathrm{~h}$. 反应结束后用饱 和食盐水洗涤有机相, 接着采用二氯甲烷 $(20 \mathrm{~mL} \times 3)$ 萃 取. 减压旋蒸除去溶剂, 粗产物采用 $V(\mathrm{DCM}): V(\mathrm{PE})=$ $2: 1$ 的洗脱剂进行硅胶色谱纯化, 最后通过 DCM 和乙 醇进行重结晶得到暗红色固体 1-OTCN (397 mg, 产率 $75 \%) .{ }^{1} \mathrm{H}$ NMR $\left(\mathrm{CDCl}_{3}, 500 \mathrm{MHz}\right) \delta: 7.65(\mathrm{~d}, J=8.5 \mathrm{~Hz}$, 4H), 7.51 (d, $J=8.5 \mathrm{~Hz}, 4 \mathrm{H}), 7.46$ (d, $J=9.0 \mathrm{~Hz}, 4 \mathrm{H}), 7.11$ $(\mathrm{d}, \quad J=8.5 \mathrm{~Hz}, 8 \mathrm{H}), 6.98(\mathrm{~d}, J=8.5 \mathrm{~Hz}, 4 \mathrm{H}), 6.86(\mathrm{~d}, J=$ $9.0 \mathrm{~Hz}, 8 \mathrm{H}), 3.81(\mathrm{~s}, 12 \mathrm{H}) ;{ }^{13} \mathrm{C} \mathrm{NMR}\left(\mathrm{CDCl}_{3}, 75 \mathrm{MHz}\right) \delta$ : $156.3,149.3,145.2,140.3,133.8,131.4,130.3,127.6$, $127.0,126.2,119.9,114.7,77.4,77.0,76.5,55.5$. MS (MALDI-TOF) calcd for $\mathrm{C}_{56} \mathrm{H}_{44} \mathrm{~N}_{4} \mathrm{O}_{4}[\mathrm{M}]^{+}$836.34; Found 836.70. Anal. calcd for $\mathrm{C}_{56} \mathrm{H}_{44} \mathrm{~N}_{4} \mathrm{O}_{4}$ : C 80.36, H 5.30, N 6.69, O 7.65; found C 80.34, H 5.30, N 6.71, O 7.65.

\section{3 钙钛矿太阳能电池的制备 ${ }^{[19]}$}

ITO 清洗处理: 将 ITO/玻璃片子在专用清洗剂中超 声 $0.5 \mathrm{~h}$ 后搓洗, 分别用去离子水、丙酮以及异丙醇超声 $10 \mathrm{~min}$, 之后用氮气将片子吹干, 紫外臭氧处理 $10 \mathrm{~min}$.

空穴传输层的制备: 将材料溶解于氯苯中, 溶液经 过滤后以 $4000 \mathrm{r} \cdot \mathrm{min}^{-1}$ 的转速旋 $60 \mathrm{~s}$, 之后在空气中以 $100{ }^{\circ} \mathrm{C}$ 退火 $10 \mathrm{~min}$.

钲钛矿层的制备: MAI 制备: 在氩气氛围下, 将 24 $\mathrm{mL}$ 甲胺 $(\omega=33 \%$, 溶于乙醇 $) 、 10 \mathrm{~mL}$ 氢碘酸 $(\omega=57 \%$, 溶于水)混溶于 $100 \mathrm{~mL}$ 乙醇中, 冰浴搅拌反应 $2 \mathrm{~h}$. 经旋 蒸后得到白色粉末, 产物通过溶解于乙醇再由乙醚析 出, 重复洗 3 次, 最后在温度为 $60{ }^{\circ} \mathrm{C}$ 的真空干燥箱干 燥过夜. 钙钛矿前驱体溶液 $\left(1.45 \mathrm{~mol} \cdot \mathrm{L}^{-1}\right)$ 是将 $\mathrm{MAI}$ 与 $\mathrm{PbCl}_{2}$ 以 $1: 1$ 的物质的量比溶于体积比为 $4: 1$ 的无水 $N, N$-dimethylformamide (DMF) 和 dimethyl sulfoxide (DMSO) 的混合溶液中制得. 之后采用反溶剂的制备方 法, 于空穴传输层上以 $4800 \mathrm{r} \cdot \mathrm{min}^{-1}$ 的转速旋涂 $20 \mathrm{~s}$, 在 旋涂开始后第 $8 \mathrm{~s}$ 注入 $200 \mu \mathrm{L}$ 氯苯. 旋涂结束后将基片 置于 $60{ }^{\circ} \mathrm{C}$ 的加热面板上退火 $1 \mathrm{~min}$, 接着置于 $80{ }^{\circ} \mathrm{C}$ 的 加热面板上退火 $2 \mathrm{~min}$, 得到黑色 $\mathrm{MAPbI}_{3}$ 薄膜. 冷却至 室温进行下一步.

电子传输层及电极的制备: 将 $\mathrm{PC}_{61} \mathrm{BM}$ 溶液 $(10 \mathrm{mg}$ $\mathrm{mL}^{-1}$ 溶于氯苯) 以 $2000 \mathrm{r} \cdot \mathrm{min}^{-1}$ 的转速旋涂 $60 \mathrm{~s}$, 待真空 蒸镀仓真空度低于 $10^{-4} \mathrm{~Pa}$, 先后蒸镀 $20 \mathrm{~nm}$ 的 $\mathrm{C}_{60}, 8 \mathrm{~nm}$ 的 BCP, $100 \mathrm{~nm}$ 的 Ag. 通过掩模板将电池器件面积控制 为 $9 \mathrm{~mm}^{2}$.

\section{References}

[1] Chai, L.; Zhong, M. Acta Phys. Sin. 2016, 65, 237902 (in Chinese). (柴否, 钟敏, 物理学报, 2016, 65, 237902.)

[2] Pan, B.; Zhu, Y.-Z.; Qiu, C.-J.; Wang, B.; Zheng, J.-Y. Acta Chim. Sinica 2018, 76, 215 (in Chinese). (潘彬, 朱义州, 邱昌娟, 王冰, 郑健禺, 化学学报, 2018, 76, 215.)

[3] Kojima, A.; Teshima, K.; Shirai, Y.; Miyasaka, T. J. Am. Chem. Soc. $\mathbf{2 0 0 9}, 131,6050$.

[4] https: //www. nrel. gov/pv/assets/images/efficiency-chart. png.

[5] Zhao, C.; Ma, Y.; Wang, Y.; Zhu, X.; Li, H.-Z.; Li, M.-Z.; Song, Y.-L. Acta Chim. Sinica 2018, 76, 9 (in Chinese). (赵聪, 马颖, 汪 洋, 周雪, 李会增, 李明珠, 宋延林, 化学学报, 2018, 76, 9.)

[6] Chen, X.-Y.; Xie, J.-J.; Wang, W.; Yuan, H.-H.; Xu, D.; Zhang, T.; He, Y.-L. Shen, H.-J. Acta Chim. Sinica 2019, 77,9 (in Chinese). (陈 薪羽, 解俊杰, 王炜, 袁慧慧, 许頔, 张奉, 何云龙, 沈沪江, 化 学学报, 2019, 77, 9.)

[7] Li, C.-P.; Lv, X.-D.; Cao, J.; Tang, Y. Chin. J. Chem. 2019, 37, 30.

[8] Wang, Y.-L.; Chang, S.; Chen, X.-M.; Ren, Y.-D.; Shi, L.-F.; Liu, Y.-H.; Zhong, H.-Z. Chin. J. Chem. 2019, 37, 616.

[9] Etgar, L.; Gao, P.; Xue, Z.; Peng, Q.; Chandiran, A. Q.; Liu, B.; Nazeeruddin, M. K.; Grätzel, M. J. Am. Chem. Soc. 2012, 134, 17396.

[10] Liu, M.; Johnston, M. B.; Snaith, H. J. Nature 2013, 501, 395.

[11] Gao, P.; Grätzel, M.; Nazeeruddin, M. K. Energy Environ. Sci. 2014, 7,2448.

[12] Green, M. A.; Ho-Baillie, A.; Snaith, H. J. Nature Photon. 2014, 8, 506.

[13] Liu, X.-D.; Li, Y.-F. J. Electrochem. 2016, 22, 315. (刘晓东, 李永 舫, 电化学, 2016, 22, 315.)

[14] Urieta-Mora, J.; García-Benito, I.; Molina-Ontoria, A.; Martín, N. Chem. Soc. Rev. 2018, 47, 8541

[15] Niu, G.-D.; Guo, X.-D.; Wang, L.-D. J. Mater. Chem. A 2015, 3, 8970.

[16] Hawash, Z.; Ono, L. K.; Raga, S. R.; Lee, M. V.; Qi, Y.-B. Chem. Mater. 2015, 27, 562.

[17] Leijtens, T.; Giovenzana, T.; Habisreutinger, S. N.; Tinkham, J. S.; Noel, N. K.; Kamino, B. A.; Sadoughi, G.; Sellinger, A.; Snaith, H. J. ACS Appl. Mater. Interfaces 2016, $8,5981$.

[18] Zhang, L.-Z.; Zhou, X.-Y.; Zhong, X.-W.; Cheng, C.; Tian, Y.-Q.; Xu, B.-M. Nano Energy 2019, 57, 248.

[19] Li, X.-D.; Wang, Y.-C.; Zhu, L.-P.; Zhang, W.-J.; Wang, H.-Q.; Fang, J.-F. ACS Appl. Mater. Interfaces 2017, 9, 31357.

[20] Sun, W.-H.; Li, Y.-L.; Yan, W.-B.; Peng, H.-T.; Ye, S.-Y.; Rao, H.-X.; Zhao, Z.-R. Liu, Z.-W. Bian, Z.-Q. Huang, C.-H. Chin. J. Chem. 2017, 35, 687.

[21] Zhang, Z,-G.; Yang, Y.-K.; Yao, J.; Xue, L.-W.; Chen, S.-S.; Li, X.-J.; Morrison, W.; Yang, C.; Li, Y.-F. Angew. Chem., Int. Ed. 2017, 129,13688

[22] Yan, W.-B.; Ye, S.-Y.; Li, Y.-L.; Sun, W.-H.; Rao, H.-X.; Liu, Z.-W.; Bian, Z.-Q.; Huang, C.-H. Adv. Energy Mater. 2016, 6, 1600474.

[23] Kim, Y. H.; Sachse, C.; Machala, M. L.; May, C.; Müller-Meskamp, L.; Leo, K. Adv. Funct. Mater. 2011, 21, 1076.

[24] Jeng, J.-Y.; Chen, K.-C.; Chiang, T.-Y.; Lin, P.-Y.; Tsai, T.-D.; Chang, Y.-C.; Guo, T.-F.; Chen, P.; Wen, T.-C.; Hsu, Y.-J. Adv. Mater. 2014, 26, 4107 .

[25] Kim, J. H.; Liang, P.-W.; Williams, S. T.; Cho, N.; Chueh, C.-C.; Glaz, M. S.; Ginger, D. S.; Jen, A. K. Y. Adv. Mater. 2015, $27,695$.

[26] Lim, K.-G.; Kim, H.-B.; Jeong, J.; Kim, H.; Kim, J. Y.; Lee, T.-W. Adv. Mater. 2014, 26, 6461

[27] Girotto, C.; Moia, D.; Rand, B. P.; Heremans, P. Adv. Funct. Mater 2011, 21,64 .

[28] Hou, F.-H.; Su, Z.-S.; Jin, F.-M.; Yan, X.-W.; Wang, L.-D.; Zhao, H.-F.; Zhu, J.-Z.; Chu, B.; Li, W.-L. Nanoscale 2015, 7, 9427.

[29] Nie, W.-Y.; Tsai, H.; Asadpour, R.; Blancon, J.; Neukirch, A. J.; Gupta1, G.; Crochet, J. J.; Chhowalla, M.; Tretiak, S.; Alam, M. A.; Wang, H.; Mohite, A. D. Science 2015, 347, 522.

[30] Zhou, H.-P.; Chen, Q.; Li, G.; Luo, S.; Song, T.; Duan, H.; Hong, Z.-R.; You, J.-B.; Liu, Y.-S.; Yang, Y. Science 2014, 345, 542.

[31] Li, Y.; Xu, Z.; Zhao, S.-L.; Qiao, B.; Huang, D.; Zhao, L.; Zhao, J.; Wang, P.; Zhu, Y.-Q.; Li, X.-G.; Liu, X.-C.; Xu, X.-R. Small 2016, 12,4902 .

[32] Yang, L.-Y.; Cai, F.-L.; Yan, Y.; Li, J.-H.; Liu, D.; Pearson, A. J.; Wang, T. Adv. Funct. Mater. 2017, 27, 1702613.

[33] Huang, C.-Y.; Fu, W.-F.; Li, C.-Z.; Zhang, Z.-Q.; Qiu, W.-M.; Shi, 
M.-M.; Heremans, P.; Jen, A. K.-Y.; Chen, H.-Z. J. Am. Chem. Soc. 2016, 138, 2528.

[34] Xue, R.-M.; Zhang, M.-Y.; Xu, G.-Y.; Zhang, J.-W.; Chen, W.-J.; Chen, H.-Y.; Yang, M.; Cui, C.-H.; Li, Y.-W.; Li, Y.-F. J. Mater. Chem. A 2018, 6, 404.

[35] Wang, J.-Y.; Liu, K.; Ma, L.-C.; Zhan, X.-W. Chem. Rev. 2016, 116, 14675.

[36] Song, Z.-H.; Wang, S.-R.; Xiao, Y.; Li, X.-G. Acta Phys. Sin. 2015, 64, 033301 (in Chinese). (宋志浩, 王世荣, 肖殷, 李祥高, 物理学 报, 2015, 64, 033301.)

[37] Zhang, H.; Wu, Y.-Z.; Zhang, W.-W.; Li, E.-P.; Shen, C.; Jiang, H.-Y.; Tian, H.; Zhu, W.-H. Chem. Sci. 2018, 9, 5919.

[38] Shen, C.; Wu, Y.-Z.; Zhang, H.; Li, E.-P.; Zhang, W.-W.; Xu, X.-J.; Wu, W.-J.; He, T.; Zhu, W.-H. Angew. Chem. Int. Ed. 2019, 58,
3784.

[39] Urieta-Mora, J.; García-Benito, I.; Molina-Ontoria, A.; Martín, N. Chem. Soc. Rev. 2018, 47, 8541.

[40] Li, H.-R.; Fu, K.-W.; Hagfeldt, A.; Grätzel, M.; Mhaisalkar, S. G.; Grimsdale, A. C. Angew. Chem. Int. Ed. 2014, 53, 4169.

[41] Yang, D.; Sano, T.; Yaguchi, Y.; Sun, H.; Sasabe, H.; Kido, J. Adv. Funct. Mater. 2018, 29, 1807556.

[42] Bi, C.; Wang, Q.; Shao, Y.-C.; Yuan, Y.-B.; Xiao, Z.-G.; Huang, J.-S. Nat. Commun. 2015, 6, 7747.

[43] Yu, H.-Z. Acta Phys. Sin. 2012, 61, 087204 (in Chinese). (於黄忠, 物理学报, 2012, 61, 087204.)

[44] Davey, M. H.; Lee, V. Y.; Miller, R. D.; Marks, T. J. J. Org. Chem. 1999, 64, 4976.

(Cheng, B.; Fan, Y.) 